\title{
Operational properties of performance engine intake air cleaners
}

The paper presents an analysis of the design of air cleaners in performance vehicles. The paper confirms that their fundamental property is a much lower flow resistance compared to standard air cleaners. The consequences of replacing a standard air filter element with a performance one have been described. The impact of this modification i.e. an increase (decrease) in the engine torque and power output has been shown. A need to perform tests related to the filtration properties of performance air cleaners has been indicated. A methodology of laboratory research has been developed for performance vehicle air cleaners. The results of the research on the filtration efficiency and accuracy characteristics have been presented along with the flow resistance of air filter elements/air cleaners depending on the dust absorbance coefficient $k_{m}$. The accuracy of the filter element has been evaluated following a Pamas particle counter measurement.

Key words: combustion engine, air cleaner, efficiency and accuracy of filtration, filter element flow resistance, size of the dust grains

\section{Introduction}

One of the factors influencing the engine repair intervals of modern combustion engines is the purity of the intake air. The said purity is ensured proper design of the air cleaner, the chemical and granulometric composition of the dust and its concentration in the intake air. The dust grains passing through to the engine penetrate the engine friction pairs damaging the structure of the mating pairs. The main friction assembly exposed to the destructive action of the dust is the piston-piston ring-cylinder assembly (P-PR-C). Following a premature wear of the said friction pair, a drop in the air tightness of the combustion chamber occurs leading to an increased blow-by to the crankcase, a reduction of the engine compression, hence a decrease in the engine power $[4,11,20]$. The most extensive engine wear is caused by grains of the size of $5-35 \mu \mathrm{m}[1,5,6,8,26]$, which is why grains of the size exceeding $5 \mu \mathrm{m}$ should be trapped by the air cleaners with a maximum (over 99.9\%) efficiency [1, 3-5, 7, 17]. This job is performed by air filter elements with a paper filtering partition characterized by high density of packing and the dust absorbance limited by the admissible resistance $\Delta \mathrm{p}_{\mathrm{fdop}}$. Nanofibers are increasingly used in the production of the filtering partitions. Such nanofibers are obtained through electrospinning or meltblown $[2,13,16,19,27]$.

With a steady value of the admissible resistance $\Delta p_{\text {fdop }}$ the extension of the vehicle mileage can be obtained through the application of:

- Filter elements of greater filtering area,

- Materials of higher dust absorbance or lower initial flow resistance.

In recent years, fitting performance air cleaners in standard vehicles has become very popular. These air cleaners are mainly characterized by low flow resistance, and the possibility of multiple regeneration [28, 29]. From the available data $[14,15,28,29]$ we know that performance air cleaners replacing the OEM (Original Equipment Manufacturer) ones usually lead to an increase in the engine torque and power output as well as vehicle acceleration. According to [32], the efficiency of the filtration of performance air cleaners determined using the AC-coarse dust $\left(d_{\text {zmax }}=200 \mu \mathrm{m}\right)$ reaches a value of $99.5-99.8 \%$ i.e. a value not much lower than that obtained for filters with a standard filtering partition measured with the AC-fine dust $\left(\mathrm{d}_{\mathrm{zmax}}=\right.$ $=80 \mu \mathrm{m}$ ). There are no data on the accuracy of filtration of performance air cleaners i.e. a parameter that, aside from the filtering efficiency, is the most decisive of the engine durability and its wear resistance.

The paper presents a methodology and results of reconnaissance research of performance air cleaners in terms of filtering efficiency and accuracy as well as flow resistance following the application of a PTC-D test dust $\left(\mathrm{d}_{\mathrm{zmax}}=\right.$ $=80 \mu \mathrm{m})-$ a local replacement dust for AC-fine according to the PN-ISO 5011 Polish standard [21].

\section{The design of performance air cleaners}

A performance air cleaner commonly denotes a nonstandard air cleaner manufactured in a technology other than traditional paper filter elements. The filtering material is a multilayer cotton or cotton synthetic fiber soaked in a dedicated oily formula, which boosts the filtering efficiency. The layers of fibers are reinforced with a metal mesh on both sides to strengthen the construction - Fig. 1 . The filtering component is pleated just like in the case of a traditional filter and then formed into the filtering element - Fig. 2. The design of the filtering layer allows its periodic regeneration consisting in cleaning with detergents and soaking it again in dedicated oil.

a)

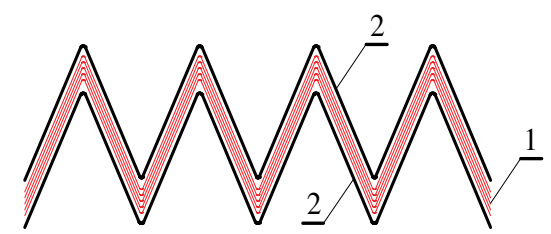

b)

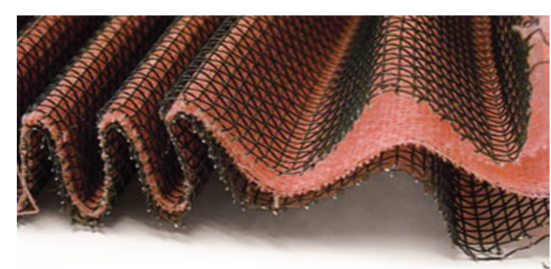

Fig. 1. The filtering layer of a performance air cleaner following the pleating procedure: 1 - fiber, 2 - protective mesh 
Performance air cleaners are made in two versions:

- as a ring element (Fig. 2a) or a panel element (Fig. 2e) allowing its fitting into the original air cleaner replacing the OEM one,

- as filtering elements of a conical or cylindrical shape (Fig. 2b, 2c, 2d) fitted on an extended flexible pipe directly to the intake system following a removal of the original air cleaner.

Filters of performance vehicles are mostly shaped into cut cones or cylinders, usually with an inner cone (counter cone - confuser) - Fig. 2d. Performance filters with a counter cone have an increased filtering area, thus a more efficiently used space. The lack of the filter casing and the inflow of air directly from the surroundings reduce the flow resistance compared to standard solutions - Fig. 3. a)

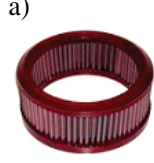

b)

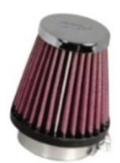

c)

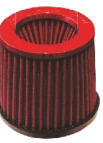

d)

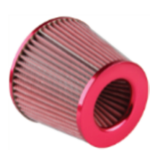

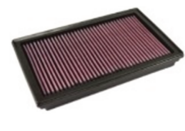

Fig. 2. Filter element: a) ring filter element, b) conical filter element, c) cylinder filter element with a counter cone, d) conical filter element with a counter cone, e) filtering panel [28, 29, 34] a)

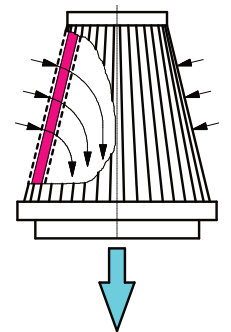

b)

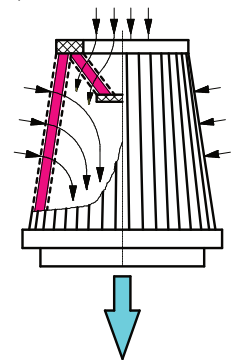

Fig. 3. Schematics of the airflow through a performance filter element: a) cone shaped, b) cone shaped with a counter-cone

Fitting of a performance filter element in the engine intake system causes the filter to suck in hot air from the engine compartment, which is why it is necessary to separate the filter from the engine with a special partition Fig. 4.

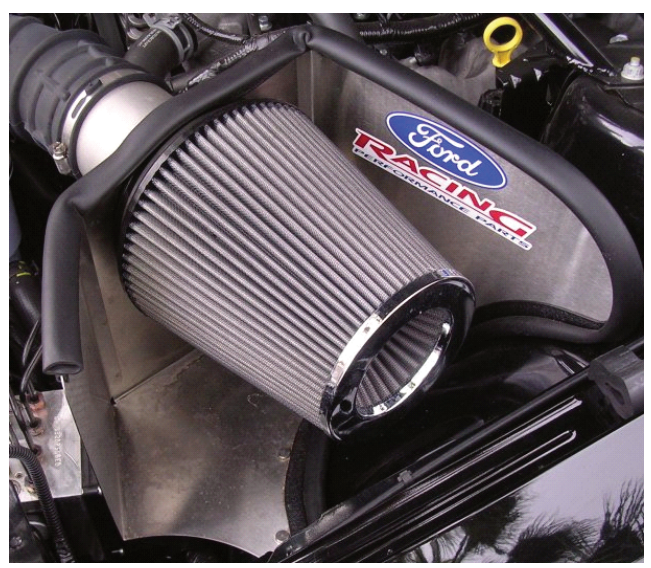

Fig. 4. A performance air cleaner in a vehicle [33]
Fitting of a performance air filter element substituting the standard one results in a reduction of the flow resistance in the engine intake system. A significant reduction of the flow resistance is obtained when conical or cylindrical filters are fitted. The elimination of the air cleaner casing results in the air flowing directly from the surroundings over the entire area of the filter element not a narrow pipe in the case of an EOM solution. The conical filter element eliminates swirls inside the filter and directs the airflow.

Figure 5 presents (determined for the nominal airflow $\left.\mathrm{Q}_{\max }\right)$ the values of the flow resistance $\Delta \mathrm{p}_{\mathrm{f}}$ of an OEM filter of a Subaru passenger car and the performance air filter elements (Fig. 6) fitted in the engine intake system. From the presented analysis we know that the conical filters (clean before operation) have their flow resistance levels lower by $60-75 \%$ compared with the OEM Subaru air cleaner.

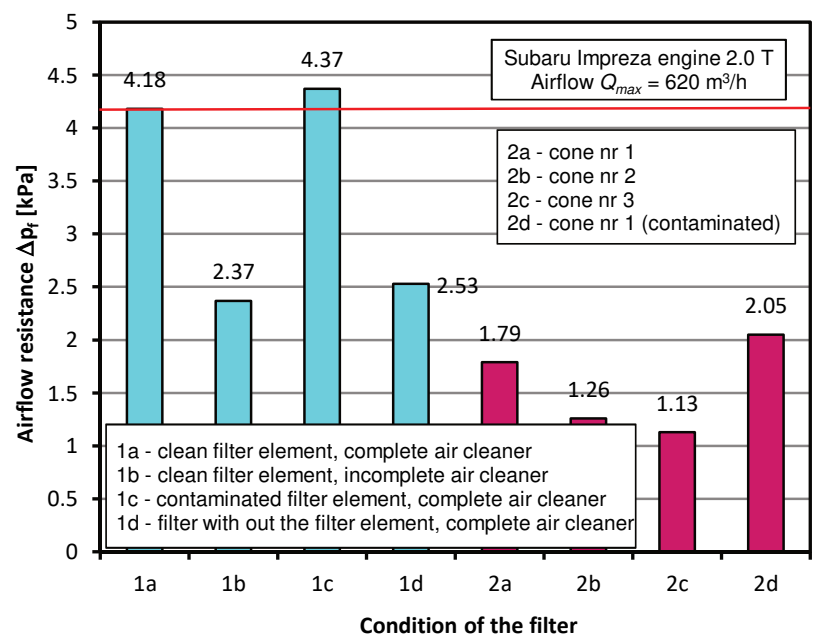

Fig. 5. Flow resistance $\Delta \mathrm{p}_{\mathrm{f}}$ of an OEM air cleaner of Subaru and the performance air cleaners

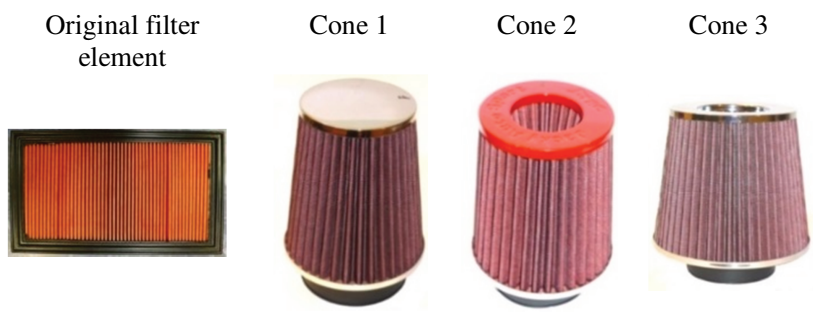

Fig. 6. Investigated filter elements of performance vehicles

\section{The effects of fitting of a performance air cleaner in a passenger car}

Fitting of a performance air cleaner in place of an OEM one usually brings measurable results such as the increase of power, torque and acceleration. This is confirmed by few experimental investigations of passenger car engines. Fig. 7 shows example results of these investigations performed on a 1.6 GTI Volkswagen Polo, where the original filter element was replaced with a performance one (BMC) [28]. An increment of power and torque were obtained on the level of $4.22 \%$ and $3.61 \%$ respectively. 


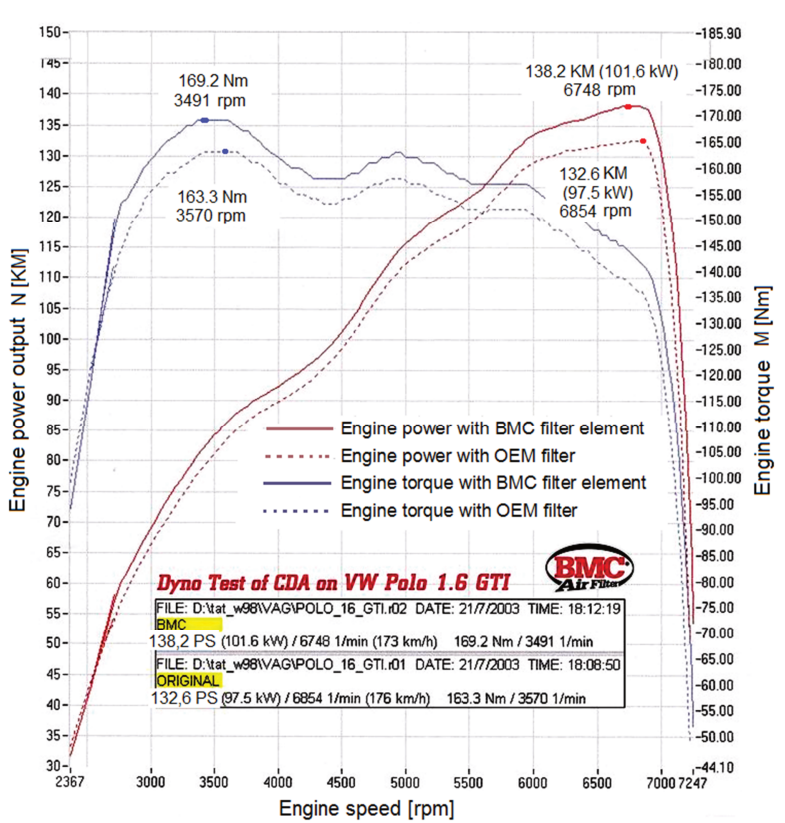

Fig. 7. Power output $N=f(n)$ and torque $M=f(n)$ characteristics of a 1.6 GTI Volkswagen Polo generated on a chassis dynamometer [28]

Table 1 presents the results of investigations performed on other vehicle engines whose OEM air cleaner was replaced with a BMC one. The percentage increment of the maximum power output $\mathrm{N}_{\mathrm{emax}}$ and the maximum torque $\mathbf{M}_{\text {omax }}$ is different for each of the tested vehicles and falls in the range between $3.2-12.9 \%$ and $2.2-10.2 \%$ respectively. Besides, the increment of the engine torque is not proportional to the increment of power (Fig. 8).

The results of investigations, in which the OEM filter element of an Alfa Romeo 156 (but in two separate engines - spark ignition 2.0 TS and diesel 1.9 JTD Sportwagon) was replaced with a performance BMC filter an then with a conical BMC filter have been presented in Fig. 9. The investigations have shown an increase in the power output and a drop in the maximum torque.

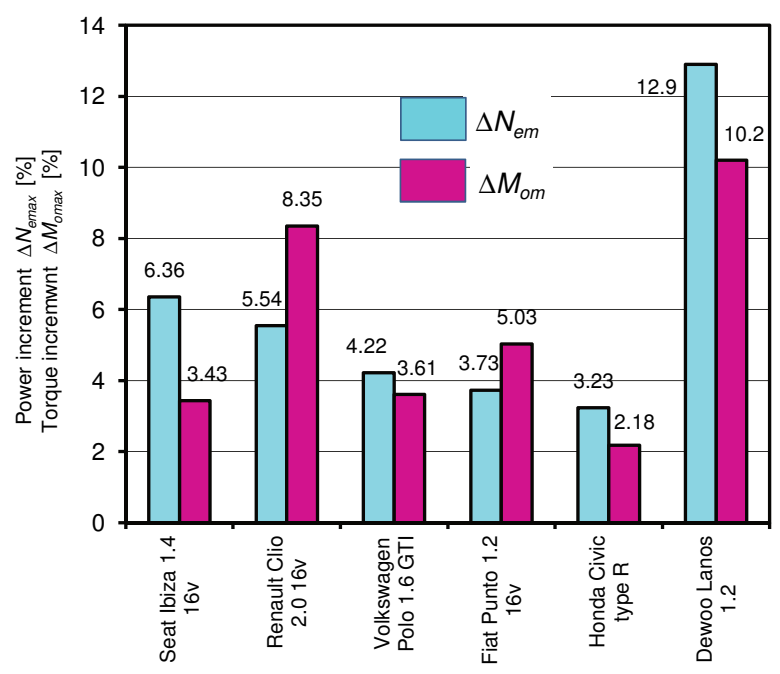

Fig. 8. Percentage increments in the power output $\mathrm{N}_{\mathrm{emax}}$ and the maximum torque $\mathrm{M}_{\text {omax }}$ following an OEM filter replacement with a performance one

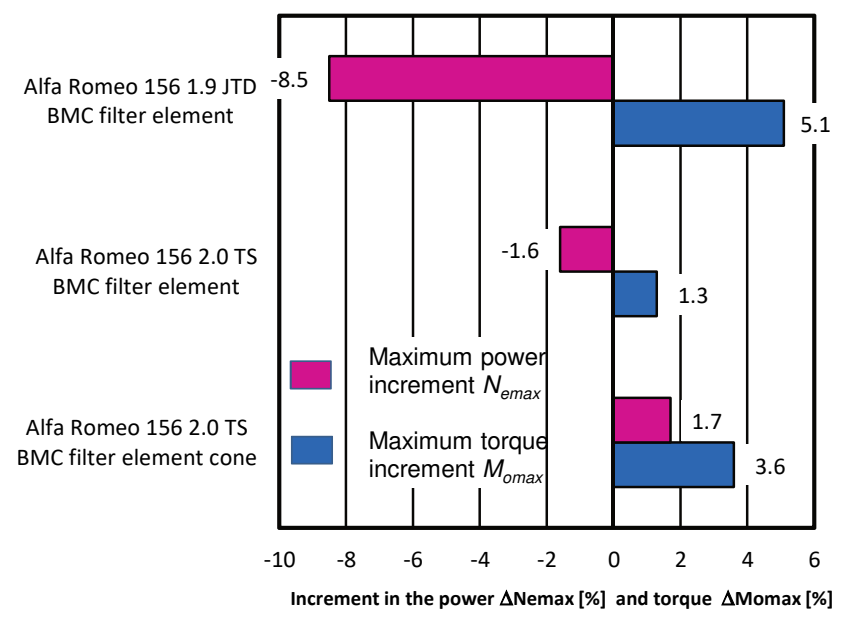

Fig. 9. Changes in the power output $\mathrm{N}_{\mathrm{emax}}$ and torque $\mathrm{M}_{\mathrm{omax}}$ of a 1.9 JTD Alfa Romeo 156 and 2.0 TS Sportwagon [14]

Table 1. Value of the maximum power output and the maximum torque for passenger vehicles fitted with a BMC CDA performance air cleaner [28-31]

\begin{tabular}{|c|c|c|c|c|c|c|}
\hline No. & Vehicle make & Engine type & $\begin{array}{c}\text { Power output } \mathrm{N}_{\mathrm{emax}} \\
\text { with an OEM air cleaner } \\
{[\mathrm{kW}] /[\mathrm{KM}]}\end{array}$ & $\begin{array}{c}\text { Increment of engine } \\
\text { maximum power output } \\
\Delta \mathrm{N}_{\mathrm{emax}}[\mathrm{kW}] /[\%]\end{array}$ & $\begin{array}{c}\text { Engine torque } \\
\mathrm{M}_{\text {omax }} \text { fitted with an OEM } \\
\text { air cleaner }[\mathrm{Nm}]\end{array}$ & $\begin{array}{l}\text { Increment of engine } \\
\text { maximum torque } \\
\Delta \mathrm{M}_{\text {omax }}[\mathrm{Nm}] /[\%]\end{array}$ \\
\hline 1 & $\begin{array}{l}\text { Seat Ibiza } 1.4 \\
16 \mathrm{v}\end{array}$ & $\begin{array}{l}\text { Spark ignition } \\
\text { naturally aspirated }\end{array}$ & $74.06 / 100.7$ & $4.7 / 6.36$ & 134.0 & $4.6 / 3.43$ \\
\hline 2 & $\begin{array}{l}\text { Renault Clio } \\
2.016 \mathrm{v}\end{array}$ & $\begin{array}{l}\text { Spark ignition } \\
\text { naturally aspirated }\end{array}$ & $119.3 / 162.2$ & $6.6 / 5.54$ & 191.6 & $16.0 / 8.35$ \\
\hline 3 & $\begin{array}{l}\text { Volkswagen } \\
\text { Polo 1.6 GTI }\end{array}$ & $\begin{array}{l}\text { Spark ignition } \\
\text { naturally aspirated }\end{array}$ & $97.53 / 132.6$ & $4.2 / 4.22$ & 163.3 & $5.9 / 3.61$ \\
\hline 4 & $\begin{array}{l}\text { Fiat Punto } 1.2 \\
16 \mathrm{v}\end{array}$ & $\begin{array}{l}\text { Spark ignition turbo- } \\
\text { charged }\end{array}$ & $59.13 / 80.4$ & $2.2 / 3.73$ & 117.4 & $5.9 / 5.03$ \\
\hline 5 & $\begin{array}{l}\text { Honda Civic } \\
\text { type R }\end{array}$ & $\begin{array}{l}\text { Spark ignition } \\
\text { naturally aspirated }\end{array}$ & $139.3 / 189.4$ & $4.5 / 3.23$ & 192.9 & $4.2 / 2.18$ \\
\hline 6 & $\begin{array}{l}\text { Dewoo Lanos } \\
1.2\end{array}$ & $\begin{array}{l}\text { Spark ignition } \\
\text { naturally aspirated }\end{array}$ & 49.35 / 67.1 & $6.4 / 12.9$ & 79.3 & $8.1 / 10.2$ \\
\hline
\end{tabular}

In the case of the 1.9 JTD diesel engine, the increase in the power output is significant and amounts to $5.1 \%$ of the maximum power $\mathrm{N}_{\mathrm{emax}}$. In both engines, upon fitting of the $\mathrm{BMC}$ conical filter element the torque decreased. In the case of the Alfa Romeo 1561.9 JTD engine, the drop in the maximum torque reaches as much as $8.5 \%$. In the case of the conical filter element fitted directly on the intake manifold, the engine torque increased but only by $1.7 \%$.

Upon replacement of the OEM filter with the performance one, a reduction of time $t_{a}$ of the vehicle reaching the required speed (for both cars) was recorded. For Alfa Romeo fitted with the 1.9 JTD engine (Sportwagon), the time 
to reach the said speed from $\mathrm{v}=0$ to $\mathrm{v}=120 \mathrm{~km} / \mathrm{h}$ was reduced from $t_{a}=13.5 \mathrm{~s}$ to $t_{a}=12.7$ s i.e. by $6 \%$. For Alfa Romeo 1562.0 TS Sportwagon, fitting the BMC conical filter element resulted in the reduction of this time from $\mathrm{t}_{\mathrm{a}}=$ $=13.9 \mathrm{~s}$ to $\mathrm{t}_{\mathrm{a}}=13.6 \mathrm{~s}$ i.e. only by $1.5 \%$. The obtained increments of the vehicle acceleration are rather small and may go unnoticed by the driver.

From the above analysis it results that the application of a filter element of lower flow resistance causes additional mass of air passing to the cylinders. Increasing the mass of air in the cylinder forces an increased mass of fuel in order to keep the stoichiometric nature of the mixture. As a result, the engine power output increases, but, as we know from the performed analysis, it is not the case for all engines that had the filters replaced. The intake system of modern vehicles is designed to ensure maximum power outputs. The diameters and lengths of the intake and exhaust ducts as well as the air cleaners are selected to obtain a dynamic engine boost relying on the wave phenomena. It consists in generating resonance between the pressure shockwaves and the frequency of the vibrations of the gas inside the intake duct. A characteristic feature of this form of boosting is the fact that the resonance occurs in a narrow range of engine speeds, usually the engine speed of the maximum torque $n_{M}$ [25]. Any parameter-related interference with such a precisely composed intake system (changing the air cleaner, changing the length of the intake duct) may lead to a fading effect of the resonance boosting, hence a shift of the maximum torque towards different engine speeds. The effect is that the replacement of the original filter element with a performance one, aside from generating a small increase in the power output and torque, does not bring measurable results (vehicle acceleration).

Performance engines are designed to reach maximum power outputs at high engine speeds $n_{N}$, reaching 11000 rpm. It makes much sense to apply performance filter elements in such engines as these filters are characterized by low flow resistance at high airflows. Engines of passenger vehicles are designed to operate at lower engine speeds $n_{N}$, not exceeding $6000 \mathrm{rpm}$.

From the above data we do not know how the fuel consumption changes after OEM to performance filter replacement. An increased mass of fuel mixed with the increased mass of air results in an increase in the hourly fuel consumption in order to keep the stoichiometric regime. The data related to fuel consumption are intentionally omitted by the manufacturers of performance filters for obvious reasons. The available data do not contain values of the filtration accuracy of the base material, let alone the value of the flow resistance of the OEM and the performance filters. This obstructs a full analysis of the impact of a performance filter on the engine parameters in a passenger car. Such data are well available for filtration papers predominantly used in filtration of vehicle consumable fluids.

It is, thus, necessary to carry out experimental investigations of the performance filter elements in terms of their efficiency, filtration accuracy and flow resistance, which would allow assessing their applicability as replacement components in passenger vehicles.

\section{Aim and subject of the research}

The aim of the research was to determine the filtration properties of a performance air cleaner and a paper filter element through the obtainment the following characteristics:

- Filtration efficiency $\varphi_{\mathrm{f}}=\mathrm{f}\left(\mathrm{k}_{\mathrm{mj}}\right)$ and flow resistance $\Delta \mathrm{p}_{\mathrm{f}}=$ $=\mathrm{f}\left(\mathrm{k}_{\mathrm{mj}}\right)$ as a function of coefficient of absorbance $\mathrm{k}_{\mathrm{mj}}$ of the filtration material,

- Dust granulometric composition downstream of the filter,

- Filtration accuracy $\mathrm{d}_{\mathrm{zmax}}=\mathrm{f}\left(\mathrm{k}_{\mathrm{mj}}\right)$ - the size of the maximum dust grains in the air downstream of the filter as a function of coefficient of dust absorbance $\mathrm{k}_{\mathrm{m}}$

where: $\mathrm{k}_{\mathrm{mj}}$ - coefficient of absorbance determining the mass of dust $m_{\mathrm{ZFj}}$ trapped per $1 \mathrm{~m}^{2}$ of active surface $\mathrm{A}_{\mathrm{cz}}$ of the filtration material until the end of a $j$-th measurement cycle expressed with a relation:

$$
\mathrm{k}_{\mathrm{mj}}=\frac{\sum_{\mathrm{j}=1}^{\mathrm{n}} \mathrm{m}_{\mathrm{zFj}}}{\mathrm{A}_{\mathrm{cz}}}\left[\mathrm{g} / \mathrm{m}^{2}\right]
$$

The objects of the investigations were $\mathrm{K} \& \mathrm{~N}$ performance air cleaners in the shape of a cut cone and a paper filter element (Fig. 10). a)

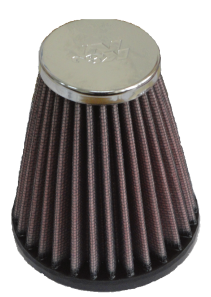

b)

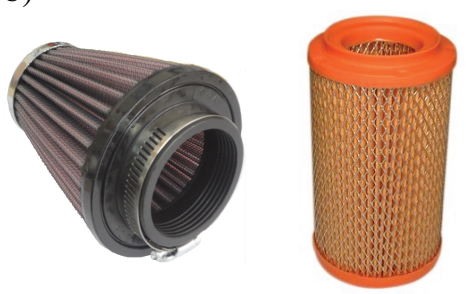

Fig. 10. Investigated air cleaners; a) performance air cleaner by K\&N, b) AP 019 air filter element

The filtration material in the performance air cleaner is a natural-synthetic fiber formed in layers and reinforced with a metal mesh on the inflow and outflow sides. The filtration material has 28 pleats of the height of $\mathrm{h}=15 \mathrm{~mm}$, which ensures an active surface area of the filtration material of $\mathrm{A}_{\mathrm{cz}}=0.0452 \mathrm{~m}^{2}$.

The investigated performance air cleaner was applied in a $V_{s s}=0.9 \mathrm{dm}^{3}$ engine of a sports car - Seicento Citymatic. The airflow passing through the filter calculated from the air demand of the engine was determined according to the principles and relations presented in $[21,22]$. At $\mathrm{n}_{\min }=$ $=1000 \mathrm{rpm}$ and the engine speed of the maximum power output $\mathrm{n}_{\mathrm{N}}=5500 \mathrm{rpm}$, it assumes the following values respectively: $Q_{\min }=25 \mathrm{~m}^{3} / \mathrm{h}$ and $\mathrm{Q}_{\mathrm{N}}=135 \mathrm{~m}^{3} / \mathrm{h}$.

The filtration rate $v_{\mathrm{F}}$ of the investigated performance air cleaner of the surface area of the filtration material $\mathrm{A}_{\mathrm{cz}}=$ $=0.0452 \mathrm{~m}^{2}$ calculated from the relation below assumes values in the range $v_{F}=0.156-0.829 \mathrm{~m} / \mathrm{s}$.

$$
v_{\mathrm{F}}=\frac{\mathrm{Q}_{\min ,(\max )}}{3600 \cdot \mathrm{A}_{\mathrm{cz}}}[\mathrm{m} / \mathrm{s}]
$$

The cylindrical filter element (AP 019) fitted in Fiat 126p was made from J.C. BINZER 796/1 VH 186 filtration paper of the surface area $A_{c z}=0.148 \mathrm{~m}^{2}$. 
The investigations of performance air cleaners were carried out in three stages. In the first stage characteristics were determined for three new performance air cleaners each operating at different filtration rates:

- $v_{\mathrm{F} 1}=0.16 \mathrm{~m} / \mathrm{s}$,

- $v_{\mathrm{F} 2}=0.32 \mathrm{~m} / \mathrm{s}$,

- $v_{\mathrm{F} 3}=0.48 \mathrm{~m} / \mathrm{s}$.

In the second stage, characteristics of a filter regenerated in detergents after the first trial were determined. Upon drying and moisturizing, the characteristics of this filter at the filtration rate of $v_{\mathrm{F} 2 \mathrm{R}}=0.32 \mathrm{~m} / \mathrm{s}$ were determined.

The third stage consisted in determining of the characteristics of a paper filter element of the filtration rate $v_{\mathrm{Fp}}=$ $=0.08 \mathrm{~m} / \mathrm{s}$. For the filtration papers, the maximum rate should not exceed $v_{\text {Fmax }}=0.07-0.12 \mathrm{~m} / \mathrm{s}[1,5,10,23,24]$.

\section{Research methodology and conditions}

The investigations were carried out on a typical flow test stand (Fig. 11) allowing determination of the fundamental characteristics: efficiency, filtration accuracy and airflow resistance for standard air filter elements of passenger cars within the airflow range $40-300 \mathrm{~m}^{3} / \mathrm{h}$ and dust concentration up to $2 \mathrm{~g} / \mathrm{m}^{3}$.

The test stand was equipped with a particle counter (Pamas - 2132 with a HCB-LD-2A-2000-1 sensor) recording the number and size of the particles in the mass flow $\mathrm{Q}$ (downstream of the filter) of the range $0.7-100 \mu \mathrm{m}$ in $\mathrm{i}=32$ measurement intervals constituting ranges limited by the diameters $\left(\mathrm{d}_{\text {zimin }}-\mathrm{d}_{\text {zimax }}\right)$. The test dust was dispensed to the dust chamber where it mixed with the intake air subsequently sucked in by the investigated air cleaner.

At an appropriate distance downstream of the investigated filter a measurement probe was placed centrally in the axis of the duct that uptakes the air to the Pamas - 2132 particle counter. The measurement duct ends with a special filter protecting the rotameter from the dust.

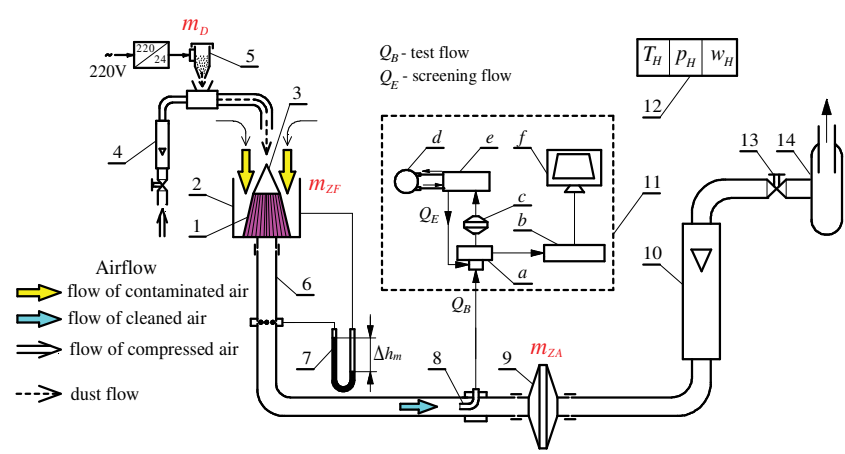

Fig. 11. Functional schematics of the filter test stand: 1 - filter, 2 - dust chamber, 3 - protective cone, 4 - rotameter, 5 - dust dispenser, 6 - measurement duct, 7 -U-type pipe manometer, 8 - measurement probe,

9 - absolute filter, 10 - rotameter, 11 - Pamas particle counter $(\mathrm{a}$ - sensor, $\mathrm{b}$ - microprocessor, $\mathrm{c}-$ test flow filter, $\mathrm{d}$ - vacuum pump, e - flow control block, f - readout panel), 12 - micromanometer, 12 - pressure, humidity and ambient temperature measurement set, 13 - airflow adjustment valve, 14 - suction fan

During the tests, a research cycle was applied, in which five counts of the dust grains in the range $0.7-50 \mu \mathrm{m}$ were programmed, divided into 28 identical measurement intervals limited with diameters $\left(\mathrm{d}_{\mathrm{zimin}}-\mathrm{d}_{\mathrm{zimax}}\right)$ with a step of $\Delta \mathrm{d}_{\mathrm{zi}}$
$=0.4 \mu \mathrm{m}(0.7-1.1 \mu \mathrm{m} ; 1.1-1.5 \mu \mathrm{m} ; 1.5-1.9 \mu \mathrm{m} ; \ldots ; 11.5-$ $-11.9 \mu \mathrm{m})$ and four intervals of diameter measurement $\left(\mathrm{d}_{\text {zimin }}-\mathrm{d}_{\text {zimax }}\right)$ 11.9-17.9 $\mu \mathrm{m}, 17.9-25 \mu \mathrm{m}, 25-42 \mu \mathrm{m}$ and $42-50 \mu \mathrm{m}$ respectively.

The tests were performed in measurement cycles resulting from time $t_{p}$ of even dust dispense to the filter. During the measurement cycle at a moment $t_{z}=1 / 2 t_{p}$, the procedure of counting of the particle number and measurement of its size was initiated in the counter downstream of the filter.

After each $\mathrm{j}$-th measurement cycle the following were determined:

1. Flow resistance $\Delta \mathrm{p}_{\mathrm{fj}}$ of the filter was determined as a drop in the static pressure upstream and downstream of the filter based on the measured (upon completion of the dust dispense) height $\Delta \mathrm{h}_{\mathrm{mj}}$ on the water manometer (U-pipe) utilizing the relation:

$$
\Delta \mathrm{p}_{\mathrm{fj}}=\frac{\Delta \mathrm{h}_{\mathrm{mj}}}{1000}\left(\rho_{\mathrm{m}}-\rho_{\mathrm{H}}\right) \mathrm{g}[\mathrm{Pa}]
$$

where: $\rho_{\mathrm{m}}-$ manometer fluid density $\left(\mathrm{H}_{2} \mathrm{O}\right)$ at the measurement temperature, $t_{H}, \rho_{H}-$ density of the atmospheric air, $\mathrm{g}$ - local gravitational acceleration.

2. The calculated value of the flow resistance $\Delta \mathrm{p}_{\mathrm{fj}}$ was converted to normal conditions $\left(\mathrm{T}_{\mathrm{n}}=293 \mathrm{~K} \mathrm{i} \mathrm{p}_{\mathrm{n}}=1013 \mathrm{kPa}\right)$ using [22]:

$$
\Delta \mathrm{p}_{\mathrm{fnj}}=\frac{\mathrm{p}_{\mathrm{H}}}{1013} \cdot \frac{293}{\mathrm{~T}_{\mathrm{H}}} \cdot \Delta \mathrm{p}_{\mathrm{f}}[\mathrm{kPa}]
$$

where: $t_{H}, p_{H}-$ average temperature and pressure during the tests.

3. The efficiency of filtration (as per [21]) - as a quotient of the mass of the dust $m_{\mathrm{ZFj}}$ trapped by the filter and the mass of the dust $m_{D j}$ introduced into the filter during the subsequent $\mathrm{j}$-th measurement cycle based on the relation:

$$
\varphi_{\mathrm{fj}}=\frac{\mathrm{m}_{\mathrm{ZFj}}}{\mathrm{m}_{\mathrm{Dj}}} 100 \%
$$

4. Coefficient of absorbance $\mathrm{k}_{\mathrm{mj}}$ of the investigated filtration material:

$$
\mathrm{k}_{\mathrm{mj}}=\frac{\sum_{\mathrm{j}=1}^{\mathrm{n}} \mathrm{m}_{\mathrm{zFj}}}{\mathrm{A}_{\mathrm{cz}}}\left[\mathrm{g} / \mathrm{m}^{2}\right]
$$

5. The number $\mathrm{N}_{\mathrm{zi}}$ of the dust grains in the airflow downstream of the filter (passed through by the filtering material) in the measurement intervals limited with diameters $\left(\mathrm{d}_{\mathrm{zimin}}-\right.$ $\left.-\mathrm{d}_{\text {zimax }}\right)$.

6. The accuracy of filtration - as the greatest size of the dust grain $\mathrm{d}_{\mathrm{zj}}=\mathrm{d}_{\mathrm{zmax}}$ in the airflow downstream of the filter. 7. Percentage share of individual dust grain fractions in the air downstream of the filter for a given test cycle:

$$
\mathrm{U}_{\mathrm{zi}}=\frac{\mathrm{N}_{\mathrm{zi}}}{\mathrm{N}_{\mathrm{z}}}=\frac{\mathrm{N}_{\mathrm{zi}}}{\sum_{\mathrm{i}=1}^{32} \mathrm{~N}_{\mathrm{zi}}} 100 \%
$$

where: $\mathrm{N}_{\mathrm{z}}=\sum_{\mathrm{i}=1}^{32} \mathrm{~N}_{\mathrm{zi}}$ - total number of dust grains passed through by the filter (from all measurement intervals) in the test cycle.

According to the PN-ISO 5011 standard [21], the dust concentration in the intake air was assumed at $\mathrm{s}=0.5 \mathrm{~g} / \mathrm{m}^{3}$. 
The actual dust concentration was determined each time upon completion of the test cycle. For the tests, PTC-D test dust was applied whose chemical and granulometric composition has been given in $[21,22]$.

\section{Analysis of the results}

The results of the investigations and the calculations of the efficiency $\varphi_{\mathrm{f}}$ and accuracy $\mathrm{d}_{\mathrm{zmax}}$ of filtration as well as the flow resistance $\Delta \mathrm{p}_{\mathrm{f}}$ of the investigated air cleaners have been presented in Fig. 12. As the mass of the trapped dust in the filtration layer grows (increase in the $\mathrm{k}_{\mathrm{m}}$ coefficient) the efficiency and accuracy of filtration and the flow resistance assume increasingly higher values. This is a result of filling of the inter-fiber spaces (pores) with dust, which is in agreement with the literature knowledge $[7,9,17,18]$.

The operation of the performance filters, whose characteristics have been presented in Fig. 12, can be divided into two stages. The first (initial) stage of the filter operation (I) is characterized by low efficiency and accuracy of filtration as well as low flow resistance. The higher the filtration rate the higher the efficiency of the filtration. After the first test cycle, the filtration efficiency for $v_{\mathrm{F} 1}=0.16 \mathrm{~m} / \mathrm{s}, v_{\mathrm{F} 2}=$ $=0.32 \mathrm{~m} / \mathrm{s}$ and $v_{\mathrm{F} 3}=0.48 \mathrm{~m} / \mathrm{s}$ assumes the values $\varphi_{\mathrm{f} 1}=$ $=46.6 \% \varphi_{\mathrm{f} 2}=61.4 \%$ and $\varphi_{\mathrm{f} 3}=86.1 \%$ respectively. During this time, the particles deposit on the elements of the porous structure (on the surface of the fibers). The condition for the particle deposition from the fluid flow on the surface of the fiber is the following relation [17]:

$$
\mathrm{F}_{\mathrm{b}}+\mathrm{F}_{\mathrm{p}}+\mathrm{F}_{\mathrm{t}}+\mathrm{F}_{\mathrm{c}}<\mathrm{F}_{\mathrm{s}}+\mathrm{F}_{\mathrm{o}}
$$

where: $F_{b}$ - inertia force of the particle, $F_{p}$ - adhesion force of the particle to the surface, $F_{t}-$ friction force, $F_{c}-$ gravity force, $F_{s}$ - force of elastic collision, $F_{o}$ - resistance force.

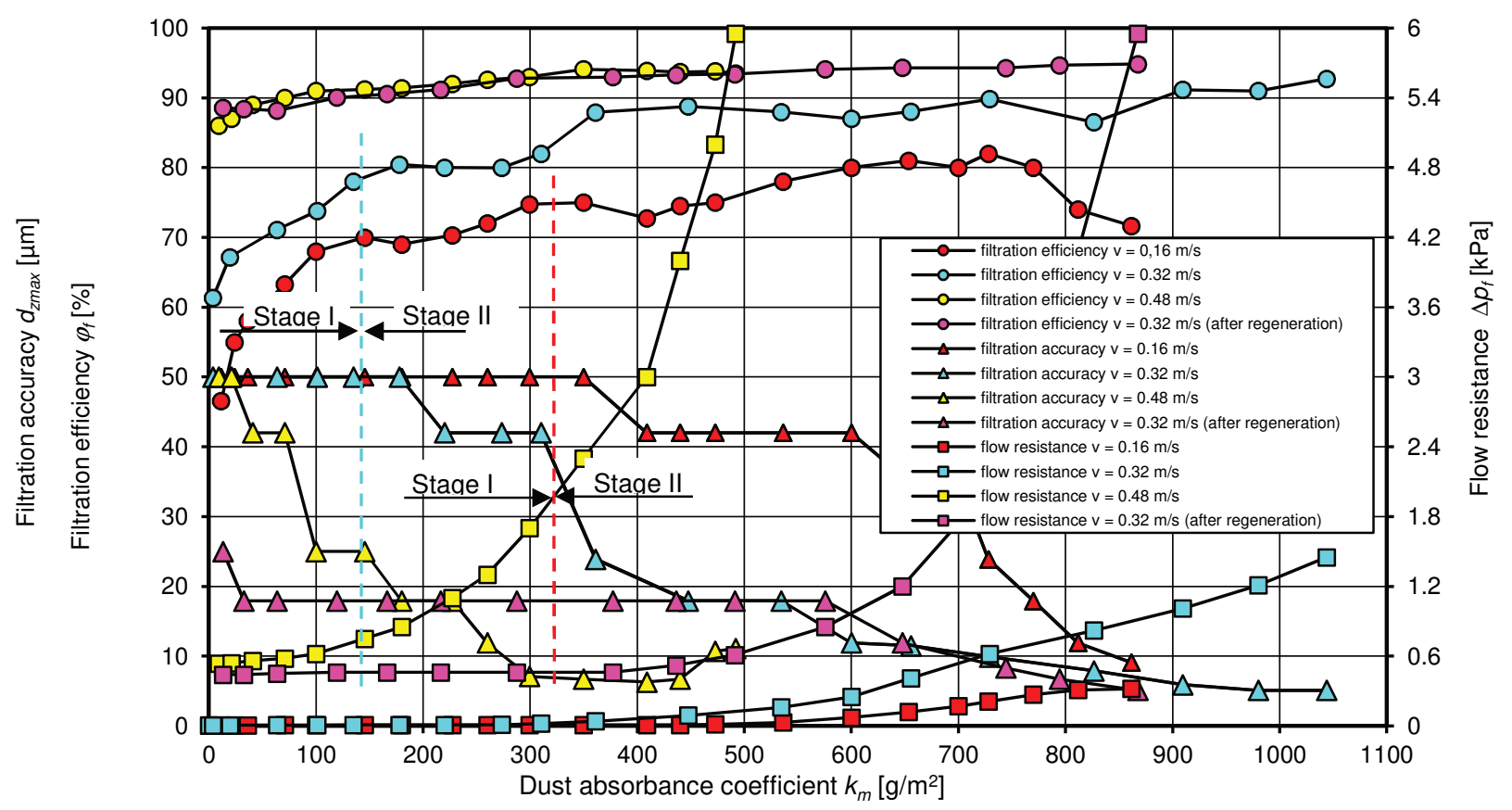

Fig. 12. Characteristics of efficiency $\varphi \mathrm{f}$, accuracy of filtration $\mathrm{d}_{\mathrm{zmax}}$ and flow resistance $\Delta \mathrm{p}_{\mathrm{f}}$ depending on the dust absorbance coefficient $\mathrm{k}_{\mathrm{m}}$ of the investigated performance air cleaners

It was assumed that the first (I) stage of the filter operation lasts until the increase in the filtering accuracy, i.e. a clear drop in the maximum size of the grains $d_{z \max }$ in the air downstream of the filter. For filter 1 (tested at $v_{F 1}=$ $=0.16 \mathrm{~m} / \mathrm{s}$ ), this period lasts until the coefficient of dust absorbance reaches $\mathrm{k}_{\mathrm{m} 1}=350 \mathrm{~g} / \mathrm{m}^{2}$. At this time the maximum size of the grains $d_{z \max }$ maintains the level of $d_{\text {zmax } 1}=$ $=50 \mu \mathrm{m}$, the filtration efficiency increases from $\varphi_{\mathrm{f} 1}=$ $46.6 \%$ to $\varphi_{\mathrm{f} 1}=75 \%$ and the flow resistance changes only slightly from $\Delta \mathrm{p}_{\mathrm{f} 1}=0.0051 \mathrm{kPa}$ to $\Delta \mathrm{p}_{\mathrm{f} 1}=0.0085 \mathrm{kPa}$. For higher filtration rates the initial stage is shorter. For filter 2 (tested at the rate of $v_{\mathrm{F} 2}=0.32 \mathrm{~m} / \mathrm{s}$ ), the first stage ends as the coefficient of absorbance reaches $\mathrm{k}_{\mathrm{m} 2}=178 \mathrm{~g} / \mathrm{m}^{2}$. For filter $3\left(v_{\mathrm{F} 3}=0.48 \mathrm{~m} / \mathrm{s}\right)$, the first stage of the filtration process is very short $\left(\mathrm{k}_{\mathrm{m} 3}=21 \mathrm{~g} / \mathrm{m}^{2}\right)$ and a clear drop in the maximum size of the grains $d_{z \max }$ downstream of the filter can be observed.
The second stage (II) of the filter operation is characterized by a further growth in the filtration efficiency, but it is less intense compared to the first stage. The first particles deposited on the porous structure form a layer that serves as another porous structure for the subsequent particles flowing with the intake air. Agglomerates form growing significantly filling the spaces between the fibers - Fig. 13 [12].

The formation of a layer of dust around the filtration components results in a modification of the gas flow conditions and a separation of subsequent inflowing dust grains. The distances among the fragments surrounded by the dust get smaller (porosity of the filtration material is reduced), which results in an increase in the flow velocity, hence increasing the hydrodynamic flow resistance in the filtration layer along with the filtering capability of the layer. The rate of formation of the agglomerates and their size mainly depend on the density of the filtering partition and the aerosol flow rate $v_{\mathrm{F}}$. 
The filter tested at $v_{\mathrm{F} 1}=0.16 \mathrm{~m} / \mathrm{s}$ reached a maximum value of efficiency $\varphi_{\mathrm{fmax} 1}=82 \%$ at $\mathrm{k}_{\mathrm{m} 1}=862 \mathrm{~g} / \mathrm{m}^{2}$ and then an abrupt drop occurred to $\varphi_{\mathrm{f} 1}=71.6 \%$. This phenomenon was accompanied by a drop in the filtration accuracy- increase in the maximum size of the grains $d_{z \max }$. The phenomenon of the efficiency drop may have been caused by the fact that the detaching forces (vacuum) exceeded the adhesion forces of the grains to the surface. An avalanche detachment of the grains took place and the grains subsequently moved further inside or were grabbed by the outlet air from the filter. As a result, the filter partly lost its properties. For this reason as well as due to the falling of the dust particles previously trapped in the filter upon completion of the measurement cycle, the tests were terminated.

a)

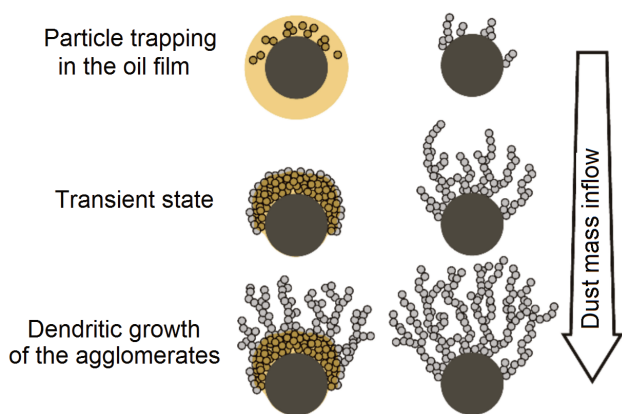

b)

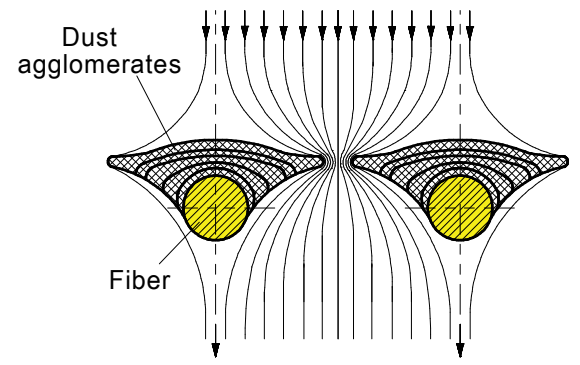

Fig. 13. Schematics of the agglomerates formation: a) subsequent phases of particle trapping in a fiber moisturized with oil and a dry one [12], b)

flow of aerosol between the fibers covered with dust agglomerates

The higher the filtration rate the higher the efficiencies of the investigated filters in the entire operating range. The filter tested at $v_{\mathrm{F} 2}=0.32 \mathrm{~m} / \mathrm{s}$ reached a maximum value of efficiency $\varphi_{\mathrm{fmax} 2}=92.7 \%\left(\mathrm{k}_{\mathrm{m} 2 \max }=1044 \mathrm{~g} / \mathrm{m}^{2}\right)$ and for the filter tested at $v_{\mathrm{F} 3}=0.48 \mathrm{~m} / \mathrm{s}$ the maximum value of filter efficiency was $\varphi_{\mathrm{fmax} 3}=93.8 \%\left(\mathrm{k}_{\mathrm{m} 3 \max }=493 \mathrm{~g} / \mathrm{m}^{2}\right)$. At the same time, the dust grains $\mathrm{d}_{\mathrm{zmax}}$ assumed increasingly lower values. At the final (II) stage, filter 1 reached a value $\mathrm{d}_{\mathrm{zmax} 1}=$ $=9.1 \mu \mathrm{m}$, filter $2 \mathrm{~d}_{\mathrm{zmax} 2}=5.5 \mu \mathrm{m}$ and filter $3 \mathrm{~d}_{\mathrm{zmax} 3}=5.1 \mu \mathrm{m}$.

With the increase of the dust trapped in the filtration layer (increased coefficient $\mathrm{k}_{\mathrm{m}}$ ) a continuous increase in the resistance $\Delta \mathrm{p}_{\mathrm{f}}$ takes place, only the intensity of the growth at the second stage of the filter operation is much higher. Besides, the flow resistance and the intensity of the growth is higher when the filtration rate increases. In the final stage of the second operating period the filters usually reach flow resistance values several times higher than the initial one $\left(\Delta \mathrm{p}_{\mathrm{f} 0}\right)$ of a given filter. For filter 1 tested at $v_{\mathrm{F} 1}=0.16 \mathrm{~m} / \mathrm{s}$, the flow resistance assumes a value $\Delta \mathrm{p}_{\mathrm{f} 1}=0.21 \mathrm{kPa}$ at $\mathrm{k}_{\mathrm{m} 1}=$ $=728 \mathrm{~g} / \mathrm{m}^{2}$. For the same value of coefficient $\mathrm{k}_{\mathrm{m}}$, the filter tested at $v_{\mathrm{F} 2}=0.32 \mathrm{~m} / \mathrm{s}$ reaches a flow resistance $\Delta \mathrm{p}_{\mathrm{f} 2}=$ $=1.45 \mathrm{kPa}$. The conical filter operating at $v_{\mathrm{F} 3}=0.48 \mathrm{~m} / \mathrm{s}$ reaches $\Delta \mathrm{p}_{\mathrm{f} 3}=3 \mathrm{kPa}$ already at $\mathrm{k}_{\mathrm{m} 3}=408 \mathrm{~g} / \mathrm{m}^{2}$. This results from the increase in the mass of the dust trapped in the filtration layer. The forming and significantly growing agglomerates fill the spaces between the fibers. A smaller distance between the surfaces of the filtering structures covered with dust results in the increase of the flow rate, hence the increased resistance $\Delta \mathrm{p}_{\mathrm{f}}$ whose value is the function of the square of the filtration rate.

Out of the three investigated performance filters, filter 2 $\left(v_{\mathrm{F} 2}=0.32 \mathrm{~m} / \mathrm{s}\right)$ had the highest dust absorbance coefficient $\mathrm{k}_{\mathrm{m} 2 \max }=1043.8 \mathrm{~g} / \mathrm{m}^{2}-$ almost twice as high compared to filter $1\left(v_{\mathrm{F} 1}=0.16 \mathrm{~m} / \mathrm{s}\right)$ and four times higher than filter 3 , not exceeding the admissible flow resistance $\Delta \mathrm{p}_{\text {fdop }}=3 \mathrm{kPa}$.

The efficiency $\varphi_{\mathrm{f}}$ and the accuracy $\mathrm{d}_{\mathrm{zmax}}$ of filtration and the flow resistance $\Delta \mathrm{p}_{\mathrm{f}}$ are different for each filter and depend on the structure of the filtration layer, dust concentration in the air, dust grain size and flow rate through the filter. In the case of the investigated filters, the changes in the efficiency $\varphi_{\mathrm{f}}$ and accuracy $\mathrm{d}_{\mathrm{zmax}}$ of filtration as well as the flow resistance depend on the airflow rate through the filter (filtration rate). As the filtration rate grows in the range $v_{F}=0.16$ $-0.48 \mathrm{~m} / \mathrm{s}$, the efficiency of filtration and flow resistance assume increasingly higher values. The highest dust absorbance coefficient $\mathrm{k}_{\mathrm{m} 2 \max }=1043.8 \mathrm{~g} / \mathrm{m}^{2}$ was obtained for filter 2 tested at the filtration rate $v_{\mathrm{F} 2}=0.32 \mathrm{~m} / \mathrm{s}$.

The explanation of this phenomenon is not easy because the process of aerosol filtration has a stochastic nature difficult to describe quantitatively and qualitatively. Trapping of the particles in the porous partition is a process depending on many forces and phenomena. The particles of contaminants and the elements of the porous structure have an irregular shape and microstructure. The grains of dust deposit evenly on the surfaces of the fibers. The porosity of the partition decreases and detachment of already deposited grains may follow under the pressure of the flowing fluid.

At low filtration rates $\left(v_{\mathrm{F} 1}=0.16 \mathrm{~m} / \mathrm{s}\right)$, the dust grains have little kinetic energy and it is much more difficult for them to penetrate inside the filtration material structure. They deposit mainly on the surfaces of the fibers located near the intake side of the partition. Since the filtration layer is moist, the intensity of the grain trapping increases. Only single grains penetrate inside the partition. As more grains arrive, they deposit on the previously trapped ones. The growing agglomerates fill the spaces between the fibers leading to the trapping of the grains on the surface of the material and blocking them from penetrating inside the filtration material. The further filtration space is not used, which results in a lower dust absorbance coefficient $\mathrm{k}_{\mathrm{m}}$ (Fig. 14). a)

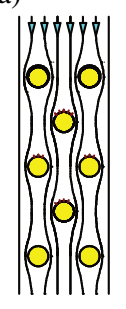

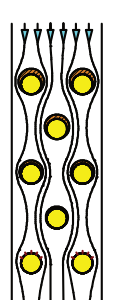

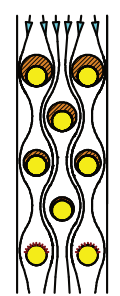

b)

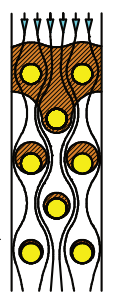

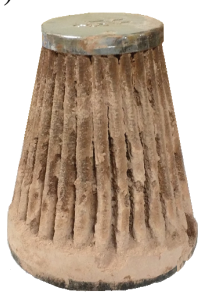

Fig. 14. Deposition of dust on the filtration material during aerosol flow at low speeds: a) change in the structure of the filtration material, b) performance filter after the tests 
In such a situation, the detaching forces (vacuum) may exceed the adhesion forces of the grains to the fibers. A grain detachment phenomenon may take place and its displacement towards the inside of the filtration structure that still has spaces free from dust. In this part of the filtration structure, the filtration process continues as at the initial stage of filtration, i.e. with lower efficiency.

At high filtration rates $\left(v_{\mathrm{F} 3}=0.48 \mathrm{~m} / \mathrm{s}\right)$ the dust grains have greater kinetic energy, which is why they move inside the partition and deposit mainly on the surface of the fibers located near the outlet part of the partition. As more grains arrive in this area, agglomerates form growing significantly and blocking the flow of air. This is the reason for the abrupt increase in the flow resistance at $v_{\mathrm{F} 3}=0.48 \mathrm{~m} / \mathrm{s}$. In this case, the filtration layer is not fully utilized. The filter reaches a value $\mathrm{k}_{\mathrm{m} 3}=408 \mathrm{~g} / \mathrm{m}^{2}$ already at $\Delta \mathrm{p}_{\mathrm{f} 3}=3 \mathrm{kPa}$.

From the above analysis, it results that the process of filtration in the filter structure is most effective (optimum) when the entire filtration space is used, the sign of which is the highest value of the dust absorbance coefficient $\mathrm{k}_{\mathrm{m}}$. Besides, the value of the flow resistance should not exceed the admissible one and the filtration efficiency should remain on a constant, high level. In the outlet air, dust grains of great size $d_{z \max }$ (indicating grain detachment from the structure due to high flow rates) do not appear. From the investigations it results that such conditions were fulfilled during the tests on the performance filter at the filtration rate $v_{\mathrm{F} 2}=0.32 \mathrm{~m} / \mathrm{s}$.

For this filtration rate, the characteristics were determined for the filter that was subjected to regeneration (detergents) after the first stage of the tests. Upon drying and moisturizing with mineral engine oil (for lack of the original moisturizer), tests on this filter were performed according to the methodology applied thus far.

The initial flow resistance of the original filter tested at $v_{\mathrm{F} 2}=0.32 \mathrm{~m} / \mathrm{s}$ has a value of $\Delta \mathrm{p}_{\mathrm{f} 3}=0.0051 \mathrm{kPa}$. The filter after regeneration and soaking in the engine oil reaches a value of $\Delta \mathrm{p}_{\mathrm{f} 3 \mathrm{p}}=0.44 \mathrm{kPa}$ i.e. much higher than that of the original filter. This most likely results from the higher engine oil viscosity (compared with the original moisturizer) that soaks in the filter structure. As the mass of the dust trapped in the filter grows (increased coefficient $k_{m}$ ), the efficiency $\varphi_{\mathrm{f}}$ and accuracy $\mathrm{d}_{\mathrm{zmax}}$ of filtration and the flow resistance $\Delta \mathrm{p}_{\mathrm{f}}$ of the performance filter assume higher values, yet, the higher levels of these parameters were not observed in the case of the original filter. An improvement of the filtration properties is particularly conspicuous during the initial period of the filter operation. The efficiency of filtration increases from $\varphi_{\text {fmax } 2}=61.8 \%$ (original filter) to $88.5 \%$ (regenerated filter) and the maximum size of the grains $d_{z \max }$ in the air downstream of the filter assumes values more than $60 \%$ lower than those of the original filter and remains on the level of $d_{z \max 1}=17.9 \mu \mathrm{m}$.

The number of the dust grains in the air downstream of the tested filter, passing through the filtering structure was recorded with the Pamas 2132 particle counter in preset measurement intervals and the results have been shown in Figs 16-18.

For each measurement cycle, along the increase in the dust grain size, their number in the air downstream of the filter decreases. In the last measurement interval of each measurement cycle there is usually one dust grain of the maximum size of $d_{z \max }$. The size of this grain was assumed as a criterion of assessment of the performance filter accuracy (Fig. 15).

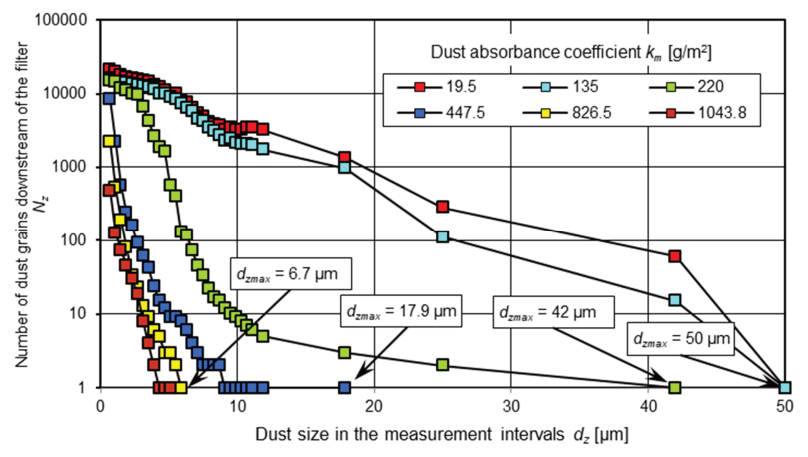

Fig. 15. Total number of dust grains in the air downstream of the performance filter during the tests at the filtration rate $v_{\mathrm{F} 2}=0.32 \mathrm{~m} / \mathrm{s}$

In subsequent measurement cycles, as the time of the performance filter operation elapsed, the total number of dust grains passed through the filter decreased and their maximum size $d_{\text {zmax }}$ was increasingly smaller. During the measurement cycle 2 (the dust absorbance coefficient $\mathrm{k}_{\mathrm{m}}=$ $=19.5 \mathrm{~g} / \mathrm{m}^{2}$ ) in the cleaned air, there were dust grains of the size not exceeding $d_{z \max }=50 \mu \mathrm{m}$ (Fig. 15). During the measurement cycle $7\left(\mathrm{k}_{\mathrm{m}}=220 \mathrm{~g} / \mathrm{m}^{2}\right)$ in the air downstream of the filter, dust grains of the maximum size of $\mathrm{d}_{\mathrm{zmax}}=$ $=42 \mu \mathrm{m}$ were recorded and during the last measurement there were dust grains not exceeding $\mathrm{d}_{\mathrm{z} \max }=5.1 \mu \mathrm{m}$.

In the subsequent measurement cycles, the total number of dust grains in the air downstream of the filter decreased but not identically for all grain sizes. Along with the coefficient of dust absorbance $\mathrm{k}_{\mathrm{m}}$ (the time of filter operation) systematically grew the number of the dust grains of small size $(0.7-1.1 \mu \mathrm{m})$ (Fig. 16). Their share $\mathrm{U}_{\mathrm{p}}$ in the total number of grains for $\mathrm{k}_{\mathrm{m}}=19.5 \mathrm{~g} / \mathrm{m}^{2}$ had the value $\mathrm{U}_{\mathrm{p}}=$ $=7.6 \%$ and in the last measurement $\left(\mathrm{k}_{\mathrm{m}}=1043.8 \mathrm{~g} / \mathrm{m}^{2}\right)$ the share amounted to $U_{p}=68 \%$. The number of the dust grains of the size $(1.1-1.5 \mu \mathrm{m})$ grew until $\mathrm{U}_{\mathrm{p}}=29.6 \%$ and then decreased. For the dust grains exceeding $\mathrm{d}_{\mathrm{z}}=1.5 \mu \mathrm{m}$, one may observe a decrease in the number of the dust grains, which indicates that it is these grains that were trapped in the filtering partition.

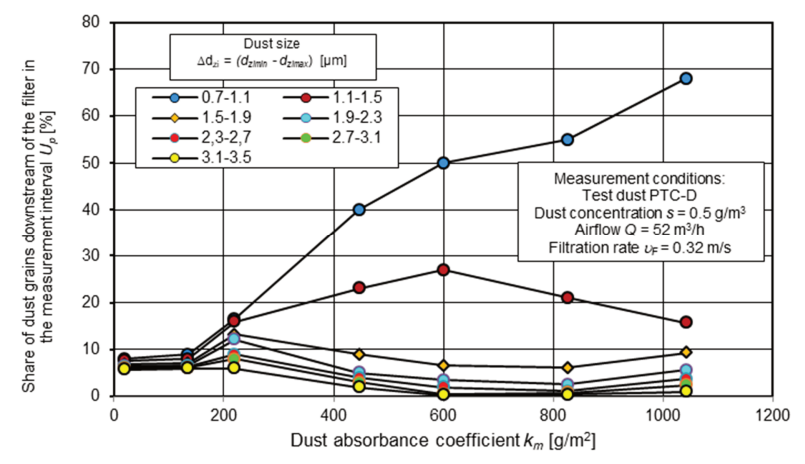

Fig. 16. Share of the dust grains in the air downstream of the performance filter during the tests at the filtration rate of $v_{\mathrm{F} 2}=0.32 \mathrm{~m} /$ for preset measurement intervals $\left(\mathrm{d}_{\text {zimin }}-\mathrm{d}_{\text {zimax }}\right)$ 
The granulometric composition of the dust upstream and downstream of the performance filter for the filtration rate $v_{\mathrm{F} 2}=0.32 \mathrm{~m} / \mathrm{s}$ has been shown in Fig. 17. For example, the share of the dust grains of the size $3.9-4.3 \mu \mathrm{m}$ in the total number of test dust grains in the air upstream of the filter is $U_{p}=16.2 \%$. In the air downstream of the filter, the share of the grains of these sizes is $\mathrm{U}_{\mathrm{p}}=4.9 \%$ for the dust absorbance coefficient $\mathrm{k}_{\mathrm{m}}=19.5 \mathrm{~g} / \mathrm{m}^{2}$ and $\mathrm{U}_{\mathrm{p}}=0.25 \%$ for $\mathrm{k}_{\mathrm{m}}=1043.8 \mathrm{~g} / \mathrm{m}^{2}$.

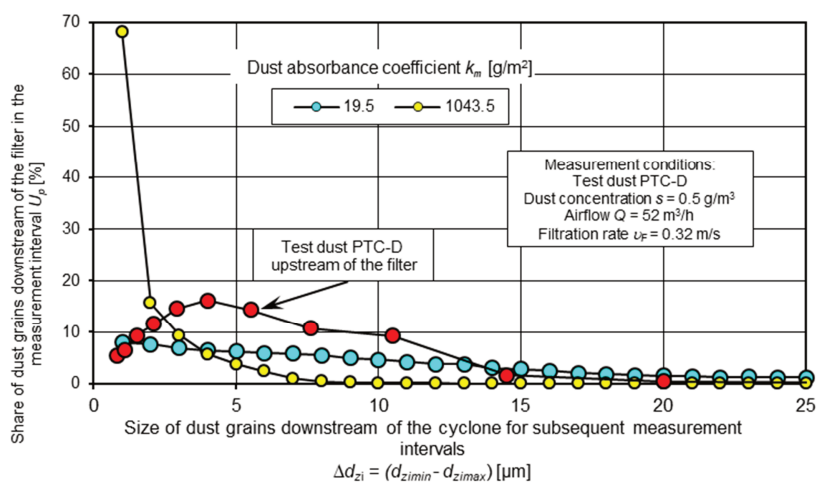

Fig. 17. Granulometric composition of dust in the air upstream and downstream of the performance filter during the tests at the filtration rate $v_{\mathrm{F} 2}=$ $=0.32 \mathrm{~m} / \mathrm{s}$ and $\mathrm{k}_{\mathrm{m}}=19.5 \mathrm{~g} / \mathrm{m}^{2}$ and $\mathrm{k}_{\mathrm{m}}=1043.8 \mathrm{~g} / \mathrm{m}^{2}$

The results of research on the efficiency $\varphi_{\mathrm{f}}$ and accuracy $d_{z m a x}$ of filtration as well as the flow resistance $\Delta p_{f}$ of the investigated performance filters and the filtration paper element have been shown in figure 18. The filter element is characterized by a better curve of the efficiency and accuracy characteristics. Performance air cleaners reach values of efficiency and accuracy that are much lower compared to the paper filter elements (Fig. 18).

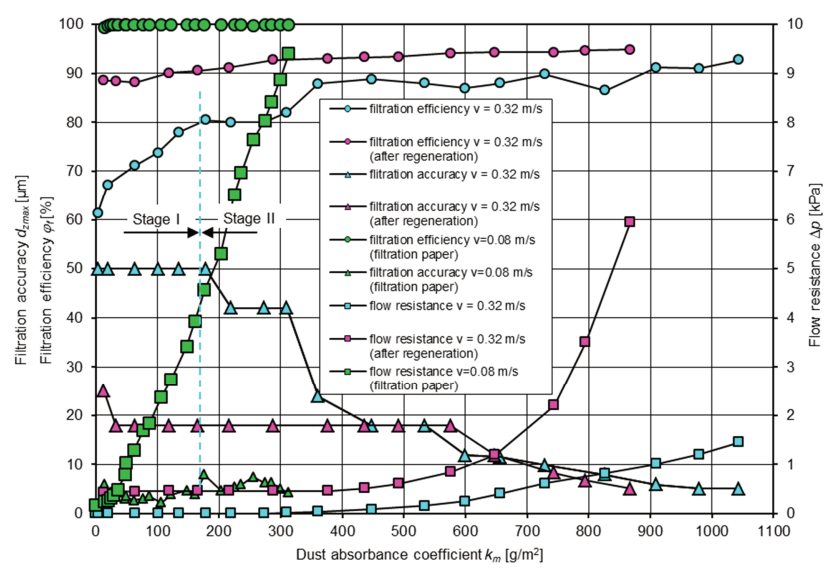

Fig. 18. Filtration efficiency $\varphi_{\mathrm{f}}$, accuracy $\mathrm{d}_{\mathrm{zmax}}$ and flow resistance $\Delta \mathrm{p}_{\mathrm{f}}$ depending on the dust absorbance coefficient $\mathrm{k}_{\mathrm{m}}$ of the investigated performance air cleaner and the filtration paper

The efficiency of filtration of a paper filter element already at its initial period of operation exceeds $99 \%$. At this time performance air cleaners reach their efficiency on the level of $\varphi_{\mathrm{f}}=46.6 \% \div 86 \%$. In the further periods of the paper filter element operation, the efficiency remains on the level of $99.9 \%$. In the initial period of the paper filter element operation the maximum size of the dust grains in the cleaned air does not exceed $\mathrm{d}_{\mathrm{zmax}}=5.9 \mu \mathrm{m}$ and quickly stabilizes at $\mathrm{d}_{\mathrm{zmax}}=2.3-3.9 \mu \mathrm{m}$. For performance air cleaners, the maximum size of the dust grains in the initial period does not exceed $\mathrm{d}_{\mathrm{zmax}}=50 \mu \mathrm{m}$ and then slowly moves towards $d_{z \max }=5.1-5.9 \mu \mathrm{m}$. Such a size of the dust grains in the cleaned air is obtained by performance filters in the last, short period of their operation.

The main period of operation of a performance filter is characterized by the presence in the cleaned air of dust grains of the size in the range $d_{z \max }=20-50 \mu \mathrm{m}$, i.e. very hazardous to the engine friction pairs. This may lead to premature wear of such pairs, a drop in the power output and a reduction in the engine durability. From the performed investigations it results that a performance air cleaner does not ensure the required efficiency $(99.5 \%)$ and filtration accuracy $(5 \mu \mathrm{m})$ of the intake air. Therefore, it should not be applied to clean intake air in passenger vehicles.

\section{Conclusions}

1) For cleaning intake air in performance cars, air cleaners commonly referred to as performance air cleaners are applied. These are cleaners of different shapes: panel, cylindrical (fitting the original casing) or conical (with the casing removed). The filtration material used in these filters is natural-synthetic fiber of a loose structure ensuring low flow resistance. The available data related to performance filters do not contain information on the basic filtration parameters such as filtration efficiency and accuracy.

2) Performance filters are used by many drivers. They are used as filter elements fitting the original casing and as independent cleaners (conical, cylindrical) fitted directly to the intake manifold replacing the original air cleaner. As a result, an increase in the power output is obtained (up to $13 \%$ ) as well as an increase in the maximum torque. In some engines, though, a drop in the power output and torque is observed. This is most likely caused by the reduced dynamic charging due to the modification of design of the original intake system.

3) For a steady filtration rate, as the mass of the dust $m_{\mathrm{ZF}}$ trapped in the performance filter (increased coefficient of absorbance $\mathrm{k}_{\mathrm{m}}$ ) grows, a slow increase in the efficiency and accuracy of filtration as well as flow resistance follows. As the filtration rate grows, the filtration efficiency assumes higher values, the flow resistance increases and the maximum size of the dust grains passed through is getting smaller. Such a change in the parameters of a performance filter results from the changes in the structure of the filtration material as the dust grains deposit on the surface of the fibers forming agglomerates.

4) In the initial period of the filter operation, performance filters are characterized by low efficiency $\left(\varphi_{\mathrm{f}}=46.6 \%-\right.$ $-86 \%)$, accuracy $\left(\mathrm{d}_{\mathrm{zmax}}=20-50 \mu \mathrm{m}\right)$ and flow resistance. They have higher initial resistance. The presence of such large dust grains in the cleaned air may result in premature wear of the piston-piston ring-piston sleeve assembly. This is one of the main reasons for a drop in the engine compression and power output. 
5) Performance filters reach their maximum efficiency and accuracy only in the last period of operation assuming the values $\varphi_{\mathrm{f}}=82.1-92.7 \%$ and $\mathrm{d}_{\mathrm{zmax}}=5.9-17.9 \mu \mathrm{m}$. These values are lower than those obtained by paper filter elements (efficiency $\varphi_{\mathrm{f}}=99.5-99.9 \%$ and accuracy $\left.\mathrm{d}_{\mathrm{zmax}}=2.9-5.1 \mu \mathrm{m}\right)$ in the entire range of their operation. This results from the loose structure of the filtering material of the performance air cleaners. The paper filter element, due to tighter structure packing, has a better curve of the efficiency and accuracy characteristics.

6) The characteristics of accuracy and efficiency of performance filters after regeneration have a better curve than the original performance filters. Increased efficien- cy and accuracy of filtration as well as flow resistance was obtained upon soaking of the filtering material in the engine oil that has higher viscosity than the original moisturizer. Regeneration of performance filters (soaked in engine oil) by using detergents is impossible.

7) Performance air cleaners, due to their low values of efficiency and accuracy of filtration, should not be used to clean intake air in passenger vehicles, as it may result in premature wear of the engine parts. The initially obtained increase in the power output resulting from the reduced flow resistance may be quickly compensated by a drop in the power output resulting from excess engine wear.

\section{Bibliography}

[1] BACZEWSKI, K., HEBDA, M. Filtracja płynów eksploatacyjnych (Filtration of operating fluids). MCNEMT. Radom 1992.

[2] BUCHER, T.M., TAFRESHI, H.V., TEPPER, G.C., Modeling performance of thinfibrous coatings with orthogonally layered nanofibers for improved aerosol filtration. Powder Technology. 2013, 249, 43-53.

[3] CHŁOPEK Z. Testing of hazards to the environment caused by particulate matter during use of vehicles. Eksploatacja $i$ Niezawodność - Maintenance and Reliability. 2012, 2, 160-170.

[4] Diesel Engine Air Filtration. PALL Corporation. 2004.

[5] DURST, M., KLEIN, G., MOSER, N. Filtration in Fahrzeugen. Die Bibliothek der Technik, Niemcy 2005.

[6] DZIUBAK, T. Operating fluids contaminantions and their effect on the wear of elements of a motor vehicle's combustion engine. The Archives of Automotive Engineering Archiwum motoryzacji. 2016, 72(2), 43-72.

[7] DZIUBAK, T., SZWEDKOWICZ, S. Experimental research on filtering fibers in a cyclone-porous barrier system. Combustion Engines. 2014, 158(3), 45-55.

[8] DZIUBAK, T. The assessment of the possibilities of improvement of the extraction evenness in multicyclone dedusters fitted in special vehicles. Combustion Engines. 2012, 4, 34-42.

[9] DZIUBAK, T. Methodology of research of filter paper characteristics to air filter of vehicle exploited at large air dustiness conditions. ZEM PAN. 2003, 4(136), 101-117.

[10] ERDMANNSDÖRFER, H. Lesttingmoglichkeiten von Papierfiltern zur Reinigung der Ansaugluft von Diselmotoren. MTZ. 1971, 32(4), 123-131.

[11] FITCH, J. Clean oil reduces engine fuel consumption. Practicing Oil Analysis Magazine. 2002, 11-12.

[12] MULLER, T.K., MEYER, J., THEBAULT, E. et al. Dust capacity increase of air filters by oil pre-treatment. Aerosol Technology. 2014.

[13] GRAFE, T., GOGINS, M., BARRIS, M. et al. Nanofibers in filtration applications in transportation. Filtration 2001 International Conference and Exposition. Chicago, Illinois, December 3-5, 2001.

[14] GT. Tuning, car audio, samochody sportowe. 2002, 3.

[15] GT. Tuning, car audio, samochody sportowe. 2002, 45.

[16] HEIKKILÄ, P., SIPILÄ, A., PELTOLA, M. et al. Electrospun PA-66 Coating on Textile Surfaces. Textile Research Journal. 2007, 77(11), 864-870.

[17] JAROSZCZYK, T., FALLON, S.L., DORGAN, J.E. et al. Development of high dust capacity multi-media engine air filters. Fluid/Particle Separation Journal. 2003, 15(2), 57-65.
[18] JAROSZCZYK, T., FALLON, S.L., PARDUE, B.A. Analysis of engine air cleaner efficiency for different size dust distributions. Fluid/Particle Separation Journal. 2002, 14(2), 75-88.

[19] JAROSZCZYK, T., PARDUE, B.A., HECKEL, S.P. et al. Engine air cleaner filtration performance - theoretical and experimental background of testing. AFS Fourteenth Annual Technical Conference and Exposition, May 1, 2001, Tampa, Florida Included in the Conference Proceedings (Session 16).

[20] KOSZAŁKA, G., SUCHECKI, A. Changes in performance and wear of small diesel engine during durability test. Combustion Engines. 2015, 3, 34-40.

[21] PN-ISO 5011. Filtry powietrza do silników spalinowych i sprężarek. Badanie działania. PKNM, 1994.

[22] PN-S-34040, Filtry powietrza. Wymagania i badania. PKN, 1996.

[23] SCHULZE, M., TAUFKIRCH, G. Papierluftfilter Nutzfahrzeugen. MTZ. 1991, 52(12).

[24] TAUFKIRCH, G., MAYR, G. Papierluftfilter für Motoren in Nutzfahrzeugen. MTZ. 1984, 45(3), 95-105.

[25] MYSŁOWSKI, J. Doładowanie silników. WKiŁ, Warszawa 2011.

[26] TRUHAN, J. Filter performance as the engine sees it. Filtration \& Separation. 1997, 34(12), 1019-1022.

[27] WANG, Q., BAI, Y., XIE, J. et al. Synthesis and filtration properties of polyimide nanofiber membrane/carbon woven fabric sandwiched hot gas filters for removal of PM 2.5 particles. Powder Technology. 2016, 292, 54-63.

[28] www.bmcairfilters.com.

[29] www.K\&Nfilters.com.

[30] www.8thcivic.com/forums/bolt-ons-all-motor/38066-f1intake.html.

[31] www.renaultsport-clio.blogspot.com/2006/09/bmc-cdacarbon-fibre-intake-air-filter.html.

[32] www.protonfilters.pl/filtry-sportowe.htm.

[33] www.google.pl/search?q=filtr+stożkowy+osłony+goracego +powietrza\&rlz=1C1CAFB_enPL683PL683\&espv=2\&biw $=1280 \&$ bih $=894 \&$ tbm $=$ isch $\&$ tbo $=u \&$ source $=$ univ $\&$ sa $=X \& v$ ed=0ahUKEwjimeD8jKbSAhWD2CwKHeS8BlgQsAQIGQ $\& d p r=1$.

[34] www.google.pl/search?q=filtry+stożkowe\&oq=filtry+stożko we \&aqs $=$ chrome. $0.69 \mathrm{i} 59 \mathrm{j} 015.9375 \mathrm{j} 0 \mathrm{j} 8 \&$ sourceid $=$ chrome $\& \mathrm{i}$ e $=$ UTF-8\#q=filtry+sto\%C5\%BCkowe+bmc\&*.

Tadeusz Dziubak, DSc., DEng. - Professor at the Faculty of Mechanics Military University of Technology, Warsaw, Poland.

e-mail: tadeusz.dziubak@wat.edu.pl 